\title{
UM ESTUDO SOBRE A INSERÇÃO DA HISTÓRIA DA MATEMÁTICA NA SALA DE AULA A PARTIR DE FONTES HISTÓRICAS: $O$ PROBLEMA 56 DO PAPIRO DE RHIND
}

\author{
Isabelle Coelho da Silva ${ }^{1}$ e Ana Carolina Costa Pereira ${ }^{2}$ \\ ${ }^{1}$ Instituto Federal de Educação, Ciência e Tecnologia do Ceará, \\ Pós-Graduação em Ensino de Ciências e Matemática - PGECM \\ ${ }^{2}$ Universidade Estadual do Ceará - UECE \\ <belle_da_silva@hotmail.com>, <carolina.pereira@uece.br>
}

DOI: $10.21439 /$ conexoes.v10i4.1154

\begin{abstract}
Resumo. Devido à necessidade de novas técnicas para o Ensino de Matemática, tem-se a História da Matemática como meio para tornar a aula um ambiente com maior aprendizado dos alunos, que pode ser inserida em sala de aula a partir do uso de fontes históricas. Neste estudo, objetivamos investigar o uso da fonte histórica, especificamente o problema 56 do Papiro de Rhind, na formação inicial do professor de Matemática como forma metodológica de conduzir o Ensino de Matemática na Educação Básica a partir da comparação de duas aplicações do problema na disciplina de História da Matemática. Esta é uma pesquisa de campo, em que utilizamos uma abordagem bibliográfica, um estudo documental e o exploratório-descritivo. Desta forma, pode-se identificar uma grande dificuldade dos alunos em tratar com a fonte histórica e explicar os cálculos sem as fórmulas previamente provadas que utilizamos atualmente. Assim, incentivamos que as fontes históricas sejam utilizadas para aprimorar o estudo de conteúdos, para que os professores possam se sentir preparados para utilizá-la em suas aulas, podendo ampliar o aprendizado dos alunos.
\end{abstract}

Palavras-chaves: História da Matemática. Papiro de Rhind. Educação Matemática.

\begin{abstract}
From the necessity of developing new techniques for the Mathematics Teaching, there is the History of Mathematics as a way to make the Mathematics class an environment and with a greater learning for the students. In this study, we aim to investigate the use of the historical source, specifically the problem 56 of the Rhind Papyrus, in the initial training of the Mathematics teacher as a methodological way to lead the Mathematics teaching at the Primary and Secondary Education from the comparison of two applications of the problem in the discipline of History of Mathematics. This is a field research, in which we used a bibliographic approach, a documental study and the descriptive-exploratory. In this way, we can identify a big difficult from the students to deal with historical sources, and to explain the calculations without the previously proved formulas that we use nowadays. Therefore, we encourage that the historical sources are used to improve the study of contents, so the teachers can feel prepared to use them in their classes, being able to expand the students learning.
\end{abstract}

Keywords: History of Mathematics. Rhind Papyrus. Mathematics Education.

\section{INTRODUÇÃO}

Conforme a sociedade muda, há a necessidade de mudanças na forma de ensinar qualquer disciplina, pois os alunos podem começar a perder o interesse devido à falta de atratividade da matéria ou a falta de conexão com a sua realidade. Neste sentido, os Parâmetros Curriculares Nacionais (PCN) afirmam que não há um único e melhor caminho para ensinar Matemática (BRASIL, 1998). Portanto, como uma dessas formas de lecionar esta disciplina, temos o uso da História da Matemática, que pode proporcionar ao aluno uma visão da construção inicial dos conceitos, em que ele poderá perceber a motivação do estudos desse conteúdo e as dúvidas existentes durante seu desenvolvimento. 

PROBLEMA 56 DO PAPIRO DE RHIND

\begin{abstract}
A partir do uso da História da Matemática, podemos apresentar para o estudante uma forma diferenciada de resolver alguns problemas matemáticos: o método que era utilizado durante o período de estudos iniciais do conceito em questão. Também podemos aproveitar esta tendência para identificar as dificuldades que os matemáticos necessitaram transpor para chegar a uma conclusão sobre o tema estudado, pois muitas vezes estas dificuldades são as mesmas que os alunos precisam enfrentar para obter uma real compreensão do conteúdo proposto em sala de aula.
\end{abstract}

Além disso, durante sua formação inicial, a maioria dos professores de matemática cursam a disciplina de História da Matemática, que faz parte de muitas das grades curriculares dos cursos de Licenciatura em Matemática. Neste disciplina espera-se que os futuros professores aprendam a utilizar esta tendência para facilitar o ensino e a aprendizagem de matemática, pois se a História da Matemática é uma proposta válida de ensino, é necessário que o licenciando saiba como utilizá-la de forma correta em sala de aula, para que não haja equívocos quanto ao uso desta tendência.

Neste sentido, Souza e Pereira (2005) afirmam que a história leva os professores a conhecer a matemática do passado, melhora a compreensão da matemática que eles irão ensinar, fornece métodos e técnicas para incorporar materiais históricos em sua prática, e amplia o entendimento do desenvolvimento do currículo e de sua profissão, o que enaltece a importância desta tendência para a formação do professor. Contudo, muitos professores ainda relatam sentir dificuldade ao tentar inserir a História da Matemática em suas aulas e, quando aplicam esta tendência em sala de aula, apenas fazem relatos bibliográficos dos matemáticos. Portanto, eles necessitariam maior instrução para conseguir incorporar os aspectos históricos na aula de matemática.

Com este intuito, vemos que, dentre as possibilidades de pesquisa sobre o uso da História da Matemática, destacam-se algumas categorias, dentre elas, a utilização de fontes históricas para o ensino, que é um meio de acesso à sociedade Matemática da antiguidade, na qual foram desenvolvidos diversos conteúdos ensinados atualmente na sala de aula da Educação Básica. Segundo, Silva (2013, p. 34) "o uso de fontes antigas se remete ao uso de textos que trazem à tona problemas que os sábios da antiguidade resolveram ou investigaram". Para este estudo, nos baseamos na utilização de fontes históricas na sala de aula de Matemática, partindo do conceito de que estas são

Todos os tipos de vestígios inscritos no passado, como livros de receita, fotografias, cinema, música, enfim, uma série de elemen- tos que auxiliariam o historiador na busca de compreender os homens do passado e como estes se estabeleceram (XAVIER, 2011, p. 1100).

Desta forma, como exemplo de fonte histórica matemática, temos o Papiro de Rhind. Este documento egípcio foi produzido por volta de 1650 a.C. e encontrase disponível para visitação no Museu Britânico. Neste papiro, há cerca de 87 problemas práticos matemáticos desta sociedade com suas soluções, envolvendo temas como álgebra, aritmética e geometria, que são atuais conteúdos da Educação Básica. Portanto, relacionamos o estudo deste papiro a uma possível contribuição metodológica para o Ensino de Matemática. Por esta razão, procuramos investigar o uso deste papiro como meio para utilização da História da Matemática a partir de fontes históricas para lecionar conteúdos matemáticos.

Para realização deste estudo utilizamos uma questão que se refere à medição de segmentos de uma pirâmide: altura, lado da base, e sua inclinação (tratada pelo termo seked), que foi entregue aos alunos com o propósito de entender a Matemática utilizada pelos egípcios e na forma em que eles a utilizavam. A partir desta atividade, foi possível iniciar uma investigação sobre o uso das fontes históricas na sala de aula da Educação Básica e como elas podem contribuir para o ensino de conteúdos matemáticos.

Deste modo, este estudo tem como objetivo principal investigar o uso da fonte histórica, especificamente o problema 56 do Papiro de Rhind, na formação inicial do professor de Matemática como forma metodológica de conduzir o Ensino de Matemática na Educação Básica a partir de duas aplicações na disciplina de História da Matemática.

\section{METODOLOGIA}

Este trabalho se fundamenta em uma pesquisa de campo, em que a primeira parte foi voltada ao estudo documental. No primeiro momento foi utilizada uma abordagem bibliográfica para tratarmos do uso das fontes históricas como meio para o Ensino de Matemática. Segundo Matos e Vieira (2001, p. 40),

[...] à medida que desenvolvemos interesses por determinados temas, vamos nos familiarizando com literaturas a esse respeito. Assim, estabelecemos uma sintonia entre a nossa proposta de reflexão e o tratamento já dispensado ao assunto por outros pesquisadores. [...] A pesquisa bibliográfica é realizada a partir de um levantamento de material com 

PROBLEMA 56 DO PAPIRO DE RHIND

dados já analisados, e publicados por meio escrito e eletrônicos, como livros, artigos científicos, páginas de Web site, sobre o tema que desejamos conhecer.

Esta abordagem também foi utilizada para tratarmos da implicação do uso da História da Matemática na formação do professor de Matemática e na sala de aula, ao mesmo tempo em que utilizamos uma análise documental para expor sobre os problemas do Papiro de Rhind, fonte histórica na qual foi baseado o estudo com os discentes.

Com base no estudo documental, podemos ver que Motta (2006, p. 17) enxerga "a História da Matemática como uma fonte de experiências humanas que podem ser trabalhadas nas atividades didáticas em Matemática, através de um diálogo com as práticas atuais e o contexto da época da produção do conceito". Além disso, a história também nos permite visualizar e escolher um caminho diferente para a resolução de alguns conteúdos, em que a forma utilizada atualmente pode não ser a mais adequada para o nosso estudo.

Em seguida, adentramos na pesquisa de campo que, segundo Marconi e Lakatos (2010, p. 169), tem o "objetivo de conseguir informações e/ou conhecimentos acerca de um problema, para o qual se procura uma resposta, ou de uma hipótese, que se queira comprovar, ou, ainda, descobrir novos fenômenos ou as relações entre eles". Dentro da pesquisa de campo, utilizamos o exploratório-descritivo, pois descreve o "estudo de caso para o qual são realizadas análises empíricas e teóricas" (MARCONI; LAKATOS, 2010, p. 169) e no qual os procedimentos de amostragens são flexíveis.

Desta forma aplicamos a pesquisa com base nas turmas dos semestres 2015.1 e 2015.2 da disciplina de História da Matemática do curso de Licenciatura em Matemática da UECE (Universidade Estadual do Ceará), em que utilizamos uma atividade para investigar a validade do uso da fonte histórica.

\section{INVESTIGANDO O USO DO PROBLEMA 56 DO PAPIRO DE RHIND COMO FONTE HIS- TÓRICA NA DISCIPLINA HISTÓRIA DA MA- TEMÁTICA}

Nas aulas da disciplina de História da Matemática na UECE é abordado, entre vários outros tópicos, a Matemática na Antiguidade, destacando a Babilônia, Mesopotâmia, Egito e Grécia. Durante a aula focada na Matemática Egípcia, foi notado que os alunos necessitavam manipular fontes que não são próximas do seu cotidiano escolar, pois eles mostraram dificuldades em lidar corretamente com as fontes apresentadas nesta aula.
Diante disto, propomos uma atividade com o uso de uma das fontes históricas mais importantes da Matemática Egípcia: o Papiro de Rhind. A atividade consistia em discutir o problema 56 deste papiro, que trata do estudo de pirâmides, em particular, a busca pela inclinação da face da pirâmide.

Este problema engloba diversos conteúdos que são vistos durante os Ensinos Fundamental e Médio, tais como, o conteúdo de pirâmides, frações, proporção, equação, unidades de medida, lados de um triângulo, multiplicação e divisão. Portanto, ele pode ser trabalhado em diversos níveis, dependendo do objetivo do professor. Para a sociedade Egípcia, este problema serviria como base de estudos para os futuros escribas, que necessitariam realizar tais cálculos para a construção das próximas pirâmides que seriam os túmulos dos faraós e de suas respectivas famílias. Desta forma, era imprescindível o seu estudo e compreensão. Além do problema 56, as questões 57 à 60 também tratam da relação entre os lados de um triângulo em uma pirâmide, então eles podem ser utilizados para o mesmo propósito deste artigo ou para estudos mais aprofundados sobre o tema.

Esta investigação foi aplicada em turmas de dois semestres consecutivos, 2015.1 e 2015.2, no curso de Licenciatura em Matemática da UECE, em que os dados e resultados da primeira aplicação serviram como base para um aperfeiçoamento da segunda aplicação. Contudo, a atividade entregue para as turmas dos dois semestres foi a mesma 1

A atividade foi precedida da aula sobre a Matemática Egípcia, em que foi apresentado um panorama sobre esta sociedade e suas contribuições para a Matemática atual. Durante a explicação sobre divisão e multiplicação egípcia, foi orientado que os alunos receberiam um trabalho com um problema desta época e eles poderiam utilizar apenas os métodos utilizados no antigo Egito, ou seja, apenas a Matemática conhecida na data de elaboração do problema. Por exemplo, se fosse necessário utilizar multiplicação e divisão para resolver o problema, os alunos deveriam utilizar aquele método ensinado na sala. A mesma instrução foi dada para os cálculos envolvendo frações, em que os egípcios apenas utilizavam frações unitárias e, portanto, os alunos deveriam procurar uma maneira (conhecida naquela época), não abordada durante a aula de explicação, para transformar frações do problema em frações unitárias para realizar os cálculos necessários.

Para realizar a multiplicação, os egípcios utilizavam apenas a duplicação, ou seja, eles multiplicavam um

\footnotetext{
${ }^{1}$ Os dados obtidos com a primeira aplicação podem ser vistos em Pereira et al (2016).
} 

PROBLEMA 56 DO PAPIRO DE RHIND

dos termos por dois afim de encontrar o resultado desejado. Por exemplo, se eles quisessem saber o resultado da multiplicação de 17 por 24, fariam primeiro uma tabela, em que colocariam na primeira coluna o número 1 , e na segunda coluna um dos termos da multiplicação (vamos escolher o 24). A Tabela 1 mostra como eles realizariam este processo, cuja sua construção será explicada a seguir Na primeira coluna, duplicava-se o número até conseguir encontrar valores que somados deem 17 (o outro termo da multiplicação). Também duplicavam-se os valores da segunda coluna até o valor máximo correspondente na primeira coluna. Em seguida, somavam-se os valores da segunda coluna correspondentes aos escolhidos na primeira coluna (os que somam 17), portanto se na primeira coluna foram escolhidos os números 1 e $16(1+16=17)$, na segunda coluna serão tomados os valores 24 e 384 , que somados resultam em 408. Portanto, $17 \times 24=408$. A divisão é feita de forma similar, mas destacando a multiplicação como operação inversa.

Tabela 1: Multiplicação de 17 por 24.

\begin{tabular}{lll}
\hline$/$ & 1 & 24 \\
& 2 & 48 \\
& 4 & 96 \\
& 8 & 192 \\
$/$ & 16 & 384 \\
\hline
\end{tabular}

Neste estudo eles deveriam traduzir o enunciado e a solução do problema, ressaltando o significado do termo seked compreender e explicar a solução do problema exposto no papiro, evidenciando a forma como os cálculos foram feitos pelos egípcios; resolver a solução com a Matemática atual; e comparar as duas soluções (similaridades, diferença, entre outros). Estas instruções foram dadas aos alunos junto com uma leitura do problema proposto, em que foram identificados alguns números na linguagem egípcia, de acordo com o que foi exposto na aula sobre a Matemática da época. Na primeira aplicação, as instruções foram dadas oralmente e na segunda aplicação, estas instruções foram entregues impressas junto com o problema utilizado.

Assim, o problema foi entregue na escrita hierática (primeira), que é a encontrada no original do papiro de Rhind, e na forma Hieroglífica, uma tradução da primeira (Figura 1).

Também foi fornecido a tradução do problema para o inglês (MAOR, 1998, p. 6-7):

\footnotetext{
${ }^{2}$ Seked é uma palavra do Egito antigo. Ela é usada para medir o declive de uma superfície inclinada. $\mathrm{O}$ "seked da pirâmide"era calculado como a razão da metade da base dividido pela altura.
}

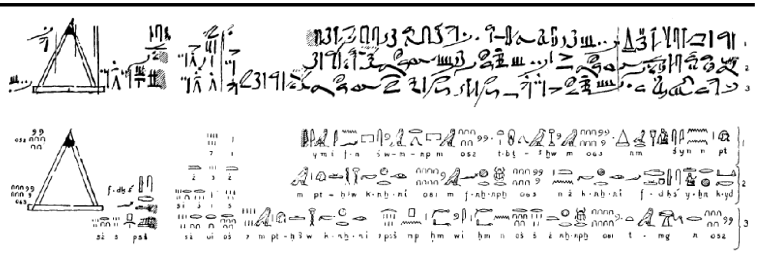

Figura 1: Problema 56 do Papiro de Rhind. Fonte: (MAOR 1998 p. 7).

"If a pyramid is 250 cubits high and the side of its base 360 cubits long, what is its seked? Ahmes's solution follows:

Take $\frac{1}{2}$ of 360 ; it makes 180 . Multiply 250 so as to get 180; it makes $\frac{1}{2} \frac{1}{5} \frac{1}{50}$ of a cubit. A cubit is 7 palms. Multiply 7 by $\frac{1}{2} \frac{1}{5} \frac{1}{50}$ :

$\begin{array}{cccc}1 & 7 & & \\ \frac{1}{2} & 3 & \frac{1}{2} & \\ \frac{1}{5} & 1 & \frac{1}{3} & \frac{1}{15} \\ \frac{1}{50} & & \frac{1}{10} & \frac{1}{25}\end{array}$

The seked is $5 \frac{1}{25} 5 \frac{1}{25}$ palms.

\subsection{Explorando os resultados da segunda aplica- ção do problema 56 do Papiro de Rhind}

Na primeira aplicação, as instruções para a realização da atividade foram dadas oralmente para os alunos. Como muitas das duplas deixaram de realizar alguns tópicos da atividade, principalmente, no que se refere à explicação da Matemática Egípcia, resolvemos entregar as instruções escritas para os alunos. Deste modo, tentamos garantir que eles entendessem o que era necessário cumprir na atividade proposta.

As turmas foram divididas em duplas (o aluno poderia trabalhar sozinho, se desejasse), para que os alunos pudessem discutir sobre a atividade proposta. Esta aplicação foi realizada na turma da disciplina de História da Matemática no semestre 2015.2, turnos tarde e noite. A atividade foi entregue para 77 alunos, com a orientação que seu cumprimento não era obrigatório. Assim, os alunos entregaram 25 atividades, $22 \mathrm{em} \mathrm{du-}$ pla e 3 individuais, que foram nomeadas "Atividade 25" à "Atividade 49" para fazer referência neste texto.

Apenas uma atividade não continha tradução para o problema, todos os outros alunos fizeram a tradução correta do problema e da solução apresentada no papiro e todos evidenciaram o significado de seked, em que 22 afirmaram que o termo significava a inclinação da face 

PROBLEMA 56 DO PAPIRO DE RHIND

da pirâmide e 03 reconheceram a palavra como uma referência à cotangente do angulo formado pela base e a face da pirâmide. É importante que nenhum dos alunos deixou de apresentar o significado de seked, mostrando que todos puderam compreender qual seria o principal questionamento do problema.

A solução antiga foi explicada em 23 trabalhos. Contudo, apenas 14 das atividades utilizaram o método egípcio para multiplicação e divisão, e apenas 8 utilizaram cálculos explicando a transformação de frações em frações unitárias. Assim, pode-se perceber que, embora quase todos os alunos tenham mostrado compreender os cálculos apresentados na resolução do papiro, apenas alguns deles assimilaram o método egípcio de realizar estes cálculos. As Figuras 2 e 3 mostram como alguns alunos realizaram e explicaram estes cálculos.

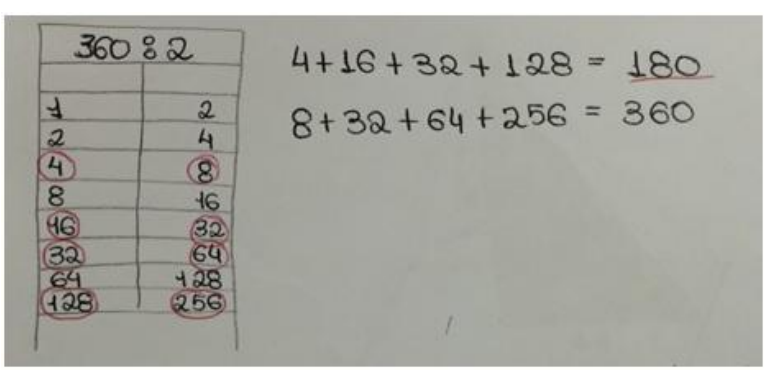

Figura 2: Método egípcio para multiplicação e divisão de números. Fonte: Atividade 37.

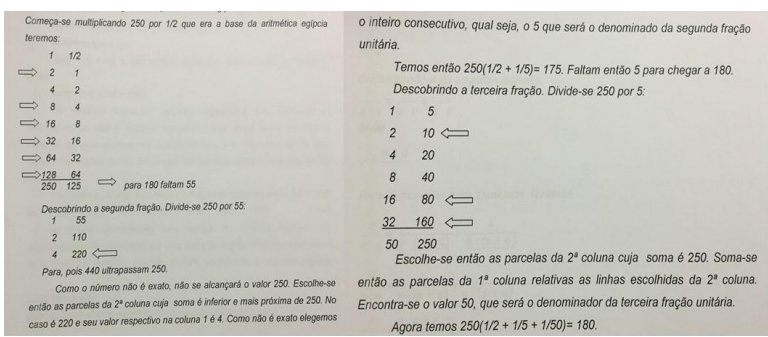

Figura 3: Transformação em frações unitárias. Fonte: Atividade 26

Em uma das atividades foi utilizado a Regra da Falsa Posiçãd ${ }^{3}$ para o cálculo de uma função do primeiro grau. Este método, também utilizado pelos egípcios no Papiro de Rhind, foi explicado para os alunos na aula sobre Matemática no Egito e apenas uma dupla visuali-

\footnotetext{
${ }^{3}$ A Regra da Falsa Posição é um método Egípcio para resolução de equações do primeiro grau, da forma $a x=b$, que consiste em adotar um valor falso para o aha (forma como os egípcios chamavam a incógnita) e, através da proporção, encontrar o valor verdadeiro procurado no problema.
}

zou sua utilização no problema 56. A Figura 4 mostra como estes alunos utilização o método.

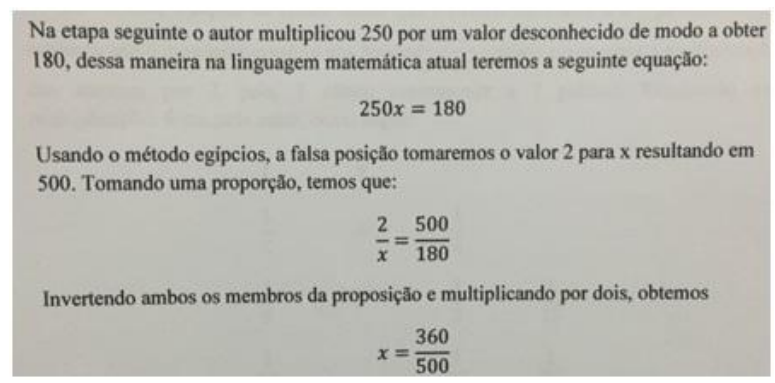

Figura 4: Utilização da Regra da Falsa Posição. Fonte: Atividade 25

A partir destas soluções, percebe-se a dificuldade dos alunos em explicar os cálculos matemáticos que não utilizam os algoritmos e fórmulas que eles usam atualmente. Por exemplo, muitos alunos não conseguiram resolver a multiplicação a partir do método Egípcio, assim como, a divisão e os cálculos com frações unitárias. Além disso, eles tiveram dificuldade em perceber a presença de uma equação do primeiro grau, como mostrado na Figura 4, tratando estes cálculos apenas como uma divisão, em que muitos resolveram pelo algoritmo atual.

A resolução com a Matemática atual foi apresentada em 22 atividades, em que os alunos utilizaram a fórmula de cotangente para calcular o seked, ou a inclinação da pirâmide, e fizeram uma proporção para transformar o resultado de cúbitos para palmos, como foi estabelecido no problema.

O gráfico da Figura 5 mostra quantos alunos cumpriram cada proposição da atividade. Percebe-se que houve uma grande diferença entre o número de alunos que entregaram a atividade e o número de alunos que fizeram a explicação da multiplicação e divisão egípcia e da transformação em frações unitárias.

Finalizando a atividade, 16 trabalhos fizeram comparações entre a Matemática Egípcia e a Matemática atual. Muitos alunos relataram a diferença no cálculo de frações, em que os egípcios utilizavam as frações unitárias. Também foi relatado as diferenças na forma de multiplicar e dividir e nas unidades de medida utilizadas.

Os alunos mencionaram que a solução do papiro e a solução que seria utilizada atualmente possuem o mesmo resultado e que elas são similares em relação ao elemento a ser encontrado (o seked). Foi relatado que os egípcios já possuíam noções dos conceitos trigonométricos, embora eles não utilizassem as fórmulas 


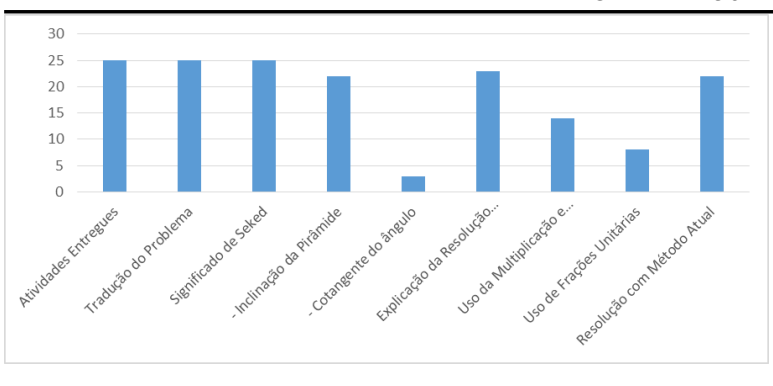

Figura 5: Cumprimento das Proposições - Segunda Aplicação. Fonte: Alunos da turma 2015.2 do curso de Matemática da UECE. Elaborado pelo autor.

trigonométricas, e que eles usavam a trigonometria no cotidiano, assim como o problema seria uma aplicação de uma situação do cotidiano deles.

Além disso, também foi relatado que os egípcios não utilizavam sinal de adição ou um símbolo para o número zero e não somavam inteiros com frações, fazendo uso das frações mistas, que a Matemática atual é mais fácil, rápida, precisa e menos complexa e que ambas as soluções utilizariam desenhos para orientar os cálculos feitos.

Desta forma, pode-se perceber que os alunos ainda possuem grande dificuldade em resolver questões sem o auxílio das fórmulas prontas que são ensinadas nas escolas. Eles também apresentam dificuldades em explicar a forma como os seus cálculos foram feitos, que também decorre do hábito de utilizar apenas as fórmulas prontas. Ressaltamos que estes alunos serão futuros professores de Matemática e questionamos se estes conhecimentos não seriam necessários para um professor da Educação Básica.

Analisando esta aplicação, também pode-se perceber que os alunos afirmam que a Matemática atual é mais rápida e fácil que a egípcia, mas nenhum deles comentam que os avanços que há na Matemática atual são devidos às descobertas e desenvolvimentos que a Matemática antiga proporcionou e que a agilidade e facilidade disponíveis para os cálculos atuais seguem de estudos feitos a partir da Matemática da antiguidade.

\subsection{Algumas conclusões da comparação das duas aplicações}

Como dito anteriormente, a primeira aplicação pode ser vista integralmente em Pereira et al. (2016). Contudo, buscaremos alguns dados desta aplicação para comparar com a aplicação mostrada aqui. A partir da análise das duas aplicações é possível ver que os alunos ainda possuem uma grande dificuldade em solucionar questões históricas utilizando apenas a Matemática da época do problema, principalmente, quando eles precisam explicar cada cálculo feito pela sociedade em questão. Contudo, houve uma melhora nesses níveis em relação às duas aplicações, pois na primeira aplicação, apenas 05 dos 24 trabalhos apresentaram os processos de multiplicação e divisão utilizados pelos egípcios, enquanto na segunda 14 dos 25 mostraram estes cálculos. Da mesma forma, houve um crescimento no número de alunos que mostraram a utilização da transformação em frações unitárias, em que 03 dos trabalhos da primeira aplicação continham esta utilização, que se comparam com 08 dos trabalhos da segunda aplicação.

Também se percebeu um maior entendimento sobre os procedimentos utilizados no método egípcio na aplicação no semestre 2015.2, em que todos os alunos mostraram entender o significado do termo seked e 23 das 25 atividades entregues explicaram a resolução antiga, contrapondo-se à 20 das 24 atividades entregues na aplicação no semestre 2015.1. Estas comparações podem ser vistas no gráfico da Figura 6, que mostra a quantidade de trabalhos que cumpriu cada proposição da atividade nas aplicações 01 e 02 , em que percebe-se uma melhora na atividade 02 em relação à atividade 01 .

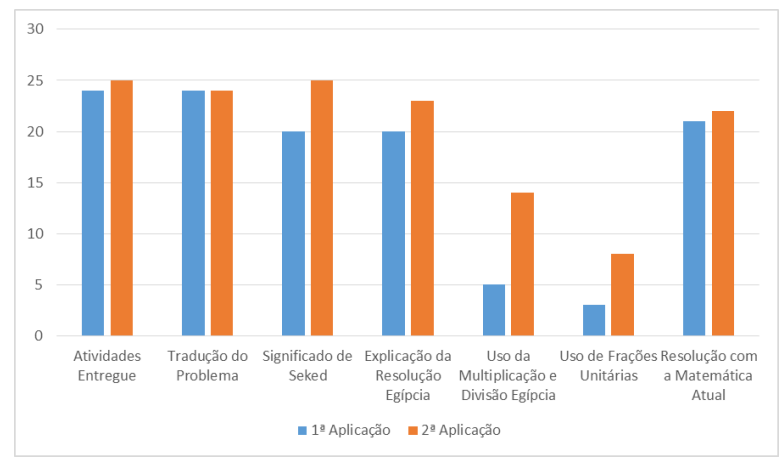

Figura 6: Comparação do cumprimento nas duas aplicações. Fonte: Alunos da turma 2015.2 do curso de Matemática da UECE. Elaborado pelo autor.

Assim, relacionamos esta melhora no tratamento da fonte histórica no semestre 2015.2 com a entrega das instruções da atividade por escrito, pois assim os alunos tiveram um maior entendimento do que seria necessário cumprir para a completa execução da atividade proposta.

Desta forma, esperamos estar instigando no aluno a necessidade da procura por uma explicação para cada cálculo feito em suas questões, assim como nas questões apresentadas a ele. Então, estaremos formando professores capacitados, que não apenas transmitam conhecimentos para os alunos sem sentido para eles ou sem conexão com fatos históricos, ou seja, o aluno não 

PROBLEMA 56 DO PAPIRO DE RHIND

precisará aceitar aquele conhecimento como sendo o único verdadeiro, sem questionamentos.

\section{CONSIDERAÇÕES FINAIS}

A História da Matemática pode proporcionar uma grande contribuição para o Ensino, pois através dela o aluno tem a oportunidade de estudar o conteúdo na forma em que ele foi desenvolvido, podendo visualizar as dificuldades epistemológicas da criação daquele conceito. Isto possibilita que o aluno compare as suas dúvidas com as questões que o matemático tinha na época de desenvolvimento deste conceito, que podem ser os mesmos questionamentos presentes nas aulas dos dias atuais.

Assim, temos as fontes históricas como meio de inserir a História nas aulas de Matemática, que objetivam comprovar os desenvolvimentos matemáticos da sociedade antiga à que pertence. Desta forma, o aluno poderá visualizar como a Matemática era feita na época desta fonte e comparar com a forma atual apresentada pelo professor em sala de aula.

Neste sentido, utilizar fontes históricas para o ensino significa propiciar ao aluno um retorno ao passado, de forma que ele possa obter um conhecimento adicional sobre o conteúdo estudado, vislumbrando a motivação do discente para estudar os conceitos apresentados e a oportunidade de comparação entre os métodos antigo e atual. $\mathrm{O}$ uso de textos históricos na sala de aula pode gerar a apreensão de conceitos matemáticos por meio de atividades que proporcionem aos alunos meios mais valiosos para a aprendizagem. Como por exemplo, para conhecer a relação sociocultural, política, econômica, filosófica de um determinado período, ou mesmo aperfeiçoar o pensamento matemático através das reflexões.

A partir de uma aplicação deste problema, concluímos que os estudantes ainda possuem dificuldades em tratar da Matemática em uma fonte histórica. Contudo, isto ocorre porque atualmente são utilizadas várias fórmulas para resolver questões e estas fórmulas já foram previamente provadas por matemáticos do passado, dispensando a necessidade da explicação do seu uso em todas as questões que envolvem o conteúdo. Como na sociedade egípcia antiga ainda não existiam estas fórmulas, os cálculos realizados nas questões necessitavam de provas ou explicações para seu uso, acarretando nesta necessidade para os alunos que resolveram a atividade proposta.

Este ainda é um estudo inicial sobre o tema, realizado apenas com as perspectivas dos licenciandos em Matemática da UECE, a partir da atividade sobre o Papiro de Rhind. Contudo, nos questionamos sobre como instigar nos alunos o cumprimento das explicações so- bre a multiplicação e divisão Egípcia e da transformação em frações unitárias, já que estes números foram considerados baixos em relação à quantidade de atividades entregues. Assim, em uma investigação mais detalhada, procuraremos entender quais os obstáculos que impediram estes alunos de compreender o método antigo.

Nosso próximo passo será fazer um estudo mais aprofundado sobre as possibilidades do uso do Papiro de Rhind como fonte histórica no Ensino de Matemática. A partir disto, estudaremos uma melhor forma de propor uma aplicação desta atividade para os alunos da Educação Básica, em que investigaremos a validade do uso desta fonte histórica com estudantes do Ensino Médio.

\section{REFERÊNCIAS}

BRASIL. Parâmetros curriculares nacionais matemática $5^{\mathrm{a}}$ a $8^{\mathrm{a}}$ série. MEC - Secretaria de Educação Fundamental, Brasília, 1998.

MAOR, E. Trigonometric Delights. New Jersey: Princeton University Press, 1998.

MARCONI, M. d. A.; LAKATOS, E. M. Fundamentos de metodologia científica $7^{\mathrm{a}}$ ed. In: Fundamentos de metodologia científica. : Atlas, 2010.

MATOS, K. S. L. d.; VIEIRA, S. L. Pesquisa educacional: o prazer de conhecer. Fortaleza: Demócrito Rocha, 2001.

MOTTA, C. D. V. B. História da matemática na educação matemática: espelho ou pintura? : Comunicar, 2006. 159 p.

PEREIRA, A. C. C.; SILVA, I. C. da; NOGUEIRA, R. S.; ALVES, F. R. V. Sobre o uso de fontes na disciplina de história da matemática: Problema 56 do papiro de rhind. Revemat: Revista Eletrônica de Educação Matemática, v. 10, n. 2, p. 243-257, 2016. Disponível em: <https://periodicos.ufsc.br/index.php/ revemat/article/view/41457> Acesso em: 6 out. 2016.

SILVA, A. P. P. d. N. A leitura de fontes antigas e a formação de um corpo interdisciplinar de conhecimentos: um exemplo a partir do Almagesto de Ptolomeu. Dissertação (Mestrado) — Universidade Federal do Rio Grande do Norte, 2013. Disponível em: <http://repositorio.ufrn.br/jspui/bitstream/123456789/ 16105/1/AnaPPNS_DISSERT.pdf> Acesso em: 10 jan 2016.

Conex. Ci. e Tecnol. Fortaleza/CE, v. 10, n. 4, p. 141 - 148, dez. 2016 
UM ESTUDO SOBRE A INSERÇÃO DA HISTÓRIA DA MATEMÁTICA NA SALA DE AULA A PARTIR DE FONTES HISTÓRICAS: O PROBLEMA 56 DO PAPIRO DE RHIND

SOUZA, A. C. P.; PEREIRA, M. Tendências em educação matemática em um curso de extensão universitária. In: Anais do XXVIII CNMAC. Santo Amaro: , 2005. p. 6. Disponível em: <http:

//www.sbmac.org.br/eventos/cnmac/cd_xxviii_cnmac/ resumos\%20estendidos/analucia_souza_SE5.pdf>.

Acesso em: 05 jan.2016.

XAVIER, É. da S. O uso das fontes históricas como ferramentas na produção de conhecimento histórico: a canção como mediador. Antíteses, v. 3, n. 6, p. 1097-1112, 2011. 